\title{
A OPAS em foco: uma história das relações internacionais em saúde na América
}

\author{
Spotlight on PAHO: a history of international \\ relations in health in the Americas
}

\author{
Carlos Henrique Assunção Paiva \\ Pesquisador da Casa de Oswaldo/Fiocruz - OPAS/OMS \\ Av. Brasil, 4036/sala 414 - Manguinhos \\ 21040-361 Rio de Janeiro - RJ - Brasil \\ cpaiva@coc.fiocruz.br
}

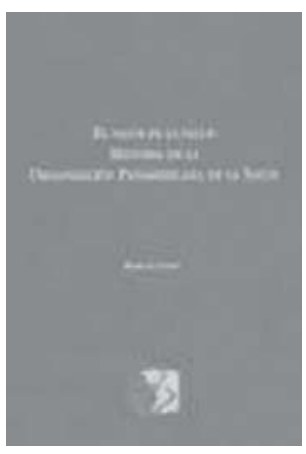

Cueto, Marcos. El valor de la salud. Historia de la Organización Panamericana de la salud. Publicación Científica y Técnica No. 600. Washington, D.C.: OPS, 2004. 211 p
$E$ l valor de la salud, do historiador peruano Marcos Cueto, já se encon tra entre aquelas indicações fundamentais para a compreensão não apenas do papel da Organização Pan-americana da Saúde (OPAS) no arranjo de idéias e programas de saúde em nosso continente, mas igualmente para o entendimento da atuação de personagens sui generis ainda pouco investigados. Este é o caso do médico norte-americano Fred L. Soper, figura atuante na saúde pública no Brasil, como membro da Fundação Rockefeller, que também se destacou na OPAS, a partir do pós-guerra. A contribuição de Cueto, no entanto, vai além da trajetória institucional da organização e de seus principais atores, pois seu livro nos faz refletir especialmente acerca das bases das relações internacionais em saúde nas Américas e no mundo, tema ainda pouco explorado pela literatura nacional e estrangeira.

Este livro de qualidade editorial e gráfica, aliado ao texto elegante, é dividido em seis capítulos, frutos de um levantamento de fontes bibliográficas e documentais de fôlego que dão substância aos argumentos e comentários do seu autor. Seu estilo aparentemente ensaístico nos oferece referências e indicações de pesquisa sobre vários temas ao longo do texto, de maneira que pode ser considerado um ponto de partida interessante para pesquisas que cubram as inúmeras lacunas sobre as relações internacionais em saúde durante o século XX.

O capítulo 1, "Los orígenes de la salud internacional en el continente americano", abre a discussão a respeito do contexto histórico que nos faz entender tanto o papel da saúde pública nos discursos e nas práticas modernizadoras no continente latino-americano, como as motivações político-econômicas que permitiram a constituição, em 1902, do primeiro organismo de cooperação internacional em saúde. $\mathrm{O}$ historiador passa em revista desde as diversas reuniões internacionais em saúde americanas e européias, a partir da Primeira Conferência Sanitária Internacional, celebrada em Paris em 1851, revê a criação da Liga das Nações, de 1918, até o arrefecimento desses primeiros ensaios de organizações internacionais, devido ao cenário das guerras mundiais.

Seu texto corrobora, de início, a posição que a literatura brasileira tem sustentado até mesmo para a "tradição nacional centralista", como aquela que cultivou Pedro II, e que não foi além de um sistema de saúde 
de alcance geográfico limitado. Cueto amplia a análise, acentuando que, em toda a América (não só na América Portuguesa), não havia ainda serviços de saúde verdadeiramente nacionais, pois estes se encontravam restritos ao controle sanitário de portos ou dos grandes centros. Com o incremento das relações comerciais intercontinentais, nesse mesmo período, tal contexto começaria a mudar. Dessa forma, "mejorar el comercio marítimo y la sanidad fue parte de este proceso de modernización y centralización de la vida política" (p. 19). Tal contexto político-econômico, ao associar-se à doutrina do panamericanismo, em boa medida permitiu a institucionalização de uma perspectiva continental da saúde, que teve início com a criação de uma oficina, posteriormente denominada União Pan-americana, a partir da Primeira Conferência Internacional Americana, ocorrida em Washington de 2 de outubro de 1889 a 19 de abril de 1890. E, deve-se lembrar, nem só do contexto econômico (relações comerciais) e político (doutrina do pan-americanismo) se alimentou a visão sanitária continental. Houve elementos específicos às tradições nacionais, que se alinharam e fortaleceram o movimento internacional. No Brasil, lugar privilegiado das lutas pela reforma sanitária desde a Primeira República, autores como Luiz Antonio de Castro Santos, Gilberto Hochman e Nísia Trindade Lima têm mostrado a "impregnação fortemente ideológica" que tomou o movimento que procurava dar às políticas e aparelhos de saúde um sentido mais amplo, associando saúde à construção de uma nova nação e à melhora das condições "eugênicas" da população brasileira.

Mas se nos fixarmos na evolução internacional, Cueto relata os primeiros passos da Oficina Sanitária Internacional, cujo primeiro diretor foi o médico norte-americano Walter Wyman (1848-1911), responsável pelo arranjo político que permitiu a criação de um organismo internacional em saúde mais forte e/ou coordenado na e para a América. Esse passo não estava descolado dos mais variados contextos nacionais, pois na maioria dos países latino-americanos, estruturas governamentais de saúde com pretensões de alcance nacional, em geral, eram submetidas à autoridade de um ministro do Interior. Nesse contexto, a atuação da Fundação Rockefeller merece destaque por sua colaboração para a criação de instituições de ensino e pesquisa, formadoras de médicos, sanitaristas e pesquisadores em saúde pública e pessoal na área de enfermagem.

O capítulo 2, intitulado "El nacimiento de una nueva Organización", como o título indica, discute, a partir do cenário apresentado no capítulo anterior, o processo de constituição do que hoje chamamos Organização Pan-americana da Saúde, no início do século passado. Com o arranjo da Conferência Internacional dos Estados Americanos, realizada no México entre 22 de outubro de 1901 e 22 de janeiro 1902, lançam-se as bases institucionais do novo organismo, que inicialmente enfrentou a desconfiança e oposição de grupos e mesmo de países. Chama a atenção, por exemplo, a resistência de políticos representantes dos interesses dos agricultores sulistas dos Estados Unidos, que viam com receio a intervenção de normas nacionais e/ou internacionais em seus interesses comerciais. 
Doente, Wyman se afastou em 1911 da direção da Oficina, quando assumiu seu segundo diretor, o médico Rupert Blue (1869-1948). Foi um contexto político e institucional complicado, por conta do ambiente instável da Primeira Guerra Mundial (1914-1918). A partir de 1920, agora chamada de Oficina Sanitária Pan-americana, assumiu a direção da organização outro médico norte-americano, Hugh S. Cumming. Sua trajetória é objeto do terceiro capítulo da obra, chamado "La consolidación de uma identidad".

Este capítulo constrói o processo de reorganização da Organização no período entre-guerras. A partir da gestão Cumming, o panamericanismo se consolidou como objetivo político e sanitário da Oficina, compromisso reafirmado na IV Conferência Internacional dos Estados Americanos, celebrada em 1923, em Santiago. Em 1922 circulou o primeiro número do Boletin Panamericano de Sanidad que, um ano depois, se transformou em Boletin de la Oficina Sanitária Panamericana. Publicado mensalmente e sem interrupções, em espanhol e português, até o final de 1996, o periódico foi uma das primeiras publicações dedicadas à saúde internacional. ${ }^{1}$

No quarto capítulo da obra, Marcos Cueto apresenta uma contribuição importante para a compreensão do processo de fortalecimento institucional pelo qual passou a Organização no pós-guerra, com a atuação do médico norte-americano Fred Soper (1947-1959). ${ }^{2}$ Formado pela John Hopkins e com ampla experiência e prestígio internacionais, como diretor regional da Rockefeller ele atuou nas campanhas de combate à malária no nordeste, atividade mais tarde retomada na Itália e no Egito. Foi personagem decisivo nos rumos da Organização a partir de 1947, quando assumiu sua direção. Soper foi o primeiro diretor que não tinha sido funcionário do Serviço de Saúde Pública dos Estados Unidos. Este dado, em parte, revela o sentido de autonomia que a Organização conquistaria com relação ao Estado norte-americano no pósguerra.

Com Soper, a organização teve novos recursos econômicos e sua equipe foi ampliada e reorganizada. No entanto, uma das tarefas mais importantes que o sanitarista teve que enfrentar, e o fez com grande êxito, foi negociar a relação da Oficina com a recém-criada Organização Mundial de Saúde (OMS), órgão a que se integrou como escritório regional, e ainda com a Organização dos Estados Americanos (OEA), à qual também se viu ligada como organismo técnico especializado.

No penúltimo capítulo do livro, chamado "La salud, el desarrollo y la participación de la comunidad", Marcos Cueto se debruça sobre um dos temas que, apesar de instigante, ainda não foi suficientemente investigado por historiadores da saúde pública brasileira e latino-ame-

\footnotetext{
${ }^{1}$ A partir de 1997 a OPAS lançou a Revista Panamericana de Salud Pública/Panamerican Journal of Public Health, que segue a tradição de sua precursora. Sobre a história do boletim, ver, entre outros, artigo de Miguel Bustamante, "Cincuentenario Del Boletin de la Oficina Panamericana - 1922-1972", Boletin de la Oficina Panamericana, ano 51, v. 72, n. 5, maio de 1972.

2 Maiores informações biográficas podem também ser obtidas em "In memoriam" no Boletin de la Oficina Panamericana, 1977.
} 
ricana. Trata-se do cenário da construção e disseminação dos discursos desenvolvimentistas, quando se ampliaram os serviços sanitários e a participação comunitária na saúde. Nesses temas, a Organização protagonizou papel importante a partir dos anos 1960, quando aconteceu a confecção da Carta de Punta del Este, dos Planos Decenais de Saúde e dos encontros de ministros de saúde das Américas. Em 1959, quando se verificou o acirramento da Guerra Fria, a partir da Revolução Cubana, o primeiro latino-americano assumiu a direção da Organização, o chileno Abraham Horwitz.

Horwitz não só deu continuidade às ações de seu antecessor, como também - para citar um exemplo - deu passo importante para a contribuição na formação de pessoal de saúde em todo continente, com o programa de bolsas que, durante o período 1958-61, contemplou mais de dois mil profissionais, um aumento de cerca de $70 \%$ com relação ao quadriênio anterior. Tais estatísticas, vale lembrar, se nivelaram aos números das bolsas concedidas a latino-americanos pelo International Health Board e International Health Division da Fundação Rockefeller, desde a década de 1920. Horwitz alcançou o auge das metas planificadoras em saúde, que tiveram no Instituto Latino-americano de Planificação Econômica e Social (ILPES), em Santiago/Chile, o centro irradiador destas idéias difundidas nos anos 1960 e 1970. Uma das estratégias de disseminação dessas propostas se deu justamente pela via pedagógica, com a organização de vários cursos de formação de planificadores para a saúde ${ }^{3}$, sobretudo em seu país natal ${ }^{4}$.

O mexicano Héctor Acuña, eleito para a direção da OPAS em 1975, não seguiu caminho diferente daquele traçado por seu antecessor. Em sintonia com a Conferência Internacional Sobre Atenção Primária de Saúde, que ocorreu em Alma-Ata em setembro de 1978, Acuña marcou sua gestão com o investimento em políticas de atenção primária à saúde, pauta que, aliás, já fazia parte das propostas da Organização pelo menos desde o final da década de 1950, e, se quisermos ir mais longe, remontava até às unidades horizontais ou postos permanentes de saúde pública, inaugurados ainda na Primeira República e que tinham caráter tipicamente universalista. A gestão Acuña ficou também marcada pela entrada de vários países do Caribe na Organização, bem como pela conseqüente criação de novos organismos especializados, vinculados à OPAS, como foi o caso do Centro de Epidemiologia do

\footnotetext{
${ }^{3}$ A inserção das ciências sociais no campo da saúde já se desenvolvia pelo menos desde os anos 1920, como apontou Nunes (2003). Castro Santos e Faria (2004) remetem à complementaridade entre o ensino de saúde pública e as ciências sociais, nos primeiros cursos de formação de Educadoras Sanitárias, em São Paulo, naquela década. No entanto, a institucionalização deste mesmo processo se radicaliza no Pós-Guerra. Exemplo disto é a mudança no padrão de formação do pessoal de saúde no período, em parte motivada pela OPAS, ao estimular a entrada de disciplinas não biológicas no currículo de formação das elites médicas latino-americanas. Se as educadoras sanitárias e as enfermeiras de saúde pública foram as primeiras profissionais a receber uma formação não estritamente biológica, agora eram os profissionais da medicina que recebiam uma formação mais diversificada, particularmente em campos de cunho "social", como a parasitologia. Hoje, as ciências sociais não ocupa lugar de grande expressão na formação médica.
}

${ }^{4}$ Veja, por exemplo, Horwitz (1973). 
Caribe (CAREC), que representou, em parte, o investimento daquela época em métodos e padrões em epidemiologia, discutidos e disseminados a partir de 1980, com a criação do Boletim Epidemiológico.

O médico brasileiro Carlyle Guerra de Macedo, que assumiu a condução da OPAS por um longo período, de 1983 até 1995, seguiu o mesmo plano de investimento em políticas de atenção primária, traçado pela gestão anterior. Neste campo, uma das experiências consideradas mais bem-sucedidas foram os programas de imunização, especialmente o de vacinação contra a poliomielite, que a partir de 1985 transformouse formal e efetivamente em uma meta de erradicação. A meta foi conquistada em 1991 (e não em 1990, conforme o planejado) e foi finalmente certificada cerca de três anos depois.

No último capítulo, "Vigência y renovación", Marcos Cueto discute questões relacionadas a alguns dos desafios atuais para as políticas de saúde do continente, desde o avanço do neoliberalismo e sua retórica e prática de um estado mínimo, até a disseminação da AIDS no continente. Neste caso, mereceu destaque a experiência do Brasil no combate a esta doença. $O$ cenário foi transformado com a emergência e atuação de importantes instituições, como é o caso do Banco Mundial, agente relevante no processo de reformas dos serviços de saúde que se desenrolam até nossos dias ${ }^{5}$. Segundo o autor, em período mais recente a organização retomou suas metas e propostas originais: “... en esos años difíciles para la salud pública, la OPS siguió reivindicando la salud como un derecho de las personas y las sociedades, y renovó sus compromisos" (p.140).

O cenário contemporâneo não é de todo mal, pois este período marca também determinada melhoria nas condições de vida das populações do continente, conquistas visíveis nos indicadores de saúde, desde a diminuição da mortalidade infantil até o aumento da sobrevida das pessoas. Inúmeros desafios foram enfrentados por George Alleyne, de Barbados, que assumiu a direção da OPAS de 1995 a 2003. A partir daí, assumiu a direção da Organização a primeira mulher a ocupar tal posto, a argentina Mirta Periago.

Compreender a história deste organismo internacional de saúde passa pela construção de verdadeira sintonia fina entre a rotina de funcionamento de uma instituição relativamente centralizada, guiada pelas mãos de seus órgãos colegiados, de seu diretor e pelos diferentes interesses nacionais em jogo, que nem sempre são representados. Como todo processo histórico é essencialmente dinâmico, a tensão entre um ponto e outro se deu e se dá de forma estrutural e circunstancialmente negociada, de modo que a política da organização, com relação aos seus países membros, revelou-se ora mais assistencialista, ora mais cooperadora, mas jamais interventora.

Assim, compreender o processo de construção da cooperação técnica em saúde na América talvez seja não apenas uma questão intelectual, para aqueles que se debruçam sobre o tema, mas um desafio político, para aqueles responsáveis por sua gestão, pois a construção

${ }^{5}$ Sobre a relação do Banco Mundial com a OMS e a OPAS ver Marcus André B. C. de Melo e Nilson do Rosário Costa, 1994. 
de uma autonomia, sem perder certo grau de inserção ou de ressonância em relação às demandas regionais, está diretamente ligada à existência e às funções desempenhadas por este importante organismo pan-americano de saúde em todo continente. E, aqui, movemo-nos do campo da história em direção ao futuro.

\section{REFERÊNCIAS BIBLIOGRÁFICAS}

Boletin de la Oficina

Panamericana

fev. 1977

Bustamante, Miguel maio de 1972

Castro Santos, Luiz A. de e Faria, Lina

Horizontes julho/dezembro 2004

Horwitz, Abraham out. 1973

Melo, Marcus André

B. C. de e Costa, Nilson do Rosário.

Nunes, Everardo 2003
"In memoriam", ano 56, Vol. LXXXII, nº 2, Washington.

"Cincuentenario del Boletin de la Oficina Panamericana - 1922-1972". Boletin de la Oficina Panamericana. Ano 51, Vol. LXXII, nº 5. Washington.

“A Cooperação Internacional e a Enfermagem de Saúde Pública no Rio de Janeiro e São Paulo: Primeiros Tempos".

Universidade São Francisco, Bragança Paulista. Vol. 22, no. 2, , pp. 123-150.

"Planificando un nuevo decenio", Boletin de la Oficina Panamericana de la Salud, Ano 52, Vol. LXXV, nº 4, Washington.

“Desenvolvimento sustentável, ajuste estrutural e política social: as estratégias da OMS/OPS e do Banco Mundial para a atenção à Saúde", Planejamento e Políticas Públicas, n.11. Brasília: IPEA. junho/dezembro de 1994

"Ciências sociais em saúde: um panorama geral". Paulete Goldenberg, Regina Marsiglia Mara Helena Gomes (orgs.) O clássico e o novo. Tendências, objetos e abordagens em ciências sociais e saúde. Rio de Janeiro: Ed. Fiocruz, pp. 57-72.



